Cahiers $d u$ MONDE RUSSE

\section{Cahiers du monde russe}

Russie - Empire russe - Union soviétique et États indépendants

$51 / 4 \mid 2010$

Sciences humaines et sociales en Russie à l'Âge d'argent

\title{
V.A. Tomsinov, éd. Zakonodatel'stvo Imperatricy Elizavety Petrovny
}

\section{Francine-Dominique Liechtenhan}

\section{(2) OpenEdition}

\section{Journals}

Édition électronique

URL : https://journals.openedition.org/monderusse/7360

DOI : $10.4000 /$ monderusse. 7360

ISSN : $1777-5388$

Éditeur

Éditions de l'EHESS

\section{Édition imprimée}

Date de publication : 25 novembre 2010

Pagination : 669-672

ISBN : 978-2-7132-2316-7

ISSN : $1252-6576$

Référence électronique

Francine-Dominique Liechtenhan, « V.A. Tomsinov, éd. Zakonodatel'stvo Imperatricy Elizavety

Petrovny ", Cahiers du monde russe [En ligne], 51/4 | 2010, mis en ligne le 09 décembre 2011, consulté le 03 septembre 2022. URL : http://journals.openedition.org/monderusse/7360 ; DOI : https://doi.org/ 10.4000 /monderusse.7360

Ce document a été généré automatiquement le 3 septembre 2022.

Tous droits réservés 


\title{
V.A. Tomsinov, éd. Zakonodatel'stvo Imperatricy Elizavety Petrovny
}

\author{
Francine-Dominique Liechtenhan
}

\section{RÉFÉRENCE}

\section{V.A. ToMsINov, éd., Zakonodatel'stvo Imperatricy Elizavety Petrovny [L'action \\ législative de l'impératrice Elizaveta Petrovna]. Moscou : Zerkalo, 2009, 257 p.}

1 L'impératrice Élisabeth (1741-1762) forme un sujet à controverse dans l'historiographie russe, anglaise, américaine, française ou allemande. Trois thèmes émergent d'une polémique, vieille de plus de deux siècles, qui divise contemporains et historiens : pour les uns, la fille de Pierre le Grand peaufina les réformes commencées par son illustre père et prépara le terrain à la politique éclairée de Catherine II ; selon les autres, on lui doit la renaissance de certaines traditions moscovites, religieuses avant tout. S'impose à la suite de ces cogitations la question (souvent polémique) de la légitimité d'une femme à la tête d'un aussi puissant État. L'histoire des femmes, conseillères, favorites, amies ou simples sujets prend une envergure particulière dans le contexte du règne d'Élisabeth, notamment à cause des lois élaborées en leur faveur (restriction des châtiments corporels, droits d'héritage, divorce).

2 Les différents tableaux de la Russie élisabéthaine esquissés par les diplomates français, anglais ou prussiens ainsi que les correspondances ministérielles si détaillées sur les conditions économiques, sociales, politiques et culturelles du pays forment un ensemble de sources d'une richesse inépuisable. Les rares monographies sur le règne de la fille de Pierre le Grand sont soit surannées, soit incompatibles avec les exigences de l'historiographie actuelle, à l'exception de Enlightened Despotism in Russia de James F. Brennan (New York, 1987). Cet auteur américain a cherché avant tout à réhabiliter la politique intérieure d'Élisabeth dont les réformes modifièrent sensiblement les structures de l'Empire russe. N'a-t-elle pas restauré le Sénat et su ménager l'Église orthodoxe, mais sans lui restituer ses droits, conformément au legs de son père? Ne fut- 
elle pas la fondatrice de l'université de Moscou? Ne refusa-t-elle pas de signer toute condamnation à la peine capitale ? Brennan réussit à effacer une série d'analyses d'un goût douteux, concentrées sur la vie mouvementée de la tsarine, exubérance que l'on pardonne en général à Catherine II.

Ce règne de vingt ans - plus particulièrement les années 1750 - représente une étape charnière pour la politique intérieure russe. De nombreux projets, qui seront redéfinis et réalisés sous Catherine II, furent alors mis en place par Petr Šuvalov : réformes fiscales, réforme du code des lois, abolition des douanes intérieures. L'évolution de l'appareil d'État s'accomplit en fonction de modèles occidentaux, mais de nombreuses concessions furent faites aux us et coutumes russes. Cet équilibre fragile fut le résultat d'une politique législative affermie par d'innombrables oukases dont les signataires variaient en fonction du contenu. Élisabeth marqua ainsi en profondeur la politique culturelle de son pays ; toujours prête à s'inspirer de l'Occident, surtout sur le plan technologique, elle se montrait soucieuse de ne pas sacrifier l'identité et l'originalité russes. Elle imposa aux artistes de respecter certains éléments issus de la tradition moscovite, notamment dans l'architecture, la peinture et la musique où émergeaient déjà des rythmes folkloriques.

4 Les textes de lois permettent d'illustrer la vie intérieure de l'Empire russe: certains oukases relèvent de la chancellerie secrète, chargée de contrôler les sujets de Sa Majesté. Les archives viennent compléter les textes de lois ; du règne de la « clémente » Élisabeth ont ainsi été conservés 6692 actes d'accusation, alors que d'Anna Ioannovna, réputée pour sa férocité, il en reste $1450^{1}$. Ces documents reflètent avec précision l'image que la souveraine voulait donner d'elle-même ainsi que de son pays et offrent de précieuses informations sur les préoccupations des Russes d'alors. La majorité des condamnés étaient des militaires, des ecclésiastiques ou fils de prêtres et des commerçants. Ces textes permettent d'approcher une certaine « classe moyenne » qui comptait beaucoup d'étrangers travaillant dans le commerce ou pour les manufactures et l'industrie naissante. Quoique plus rares, les correspondances de ces négociants peuvent compléter le tableau de ce qu'un diplomate français appelait « un pays d'inquisition » et illustrer une partie au moins de la vie intérieure du pays.

5 Les textes de lois permettent aussi d'illustrer la politique étrangère de ce règne. La guerre de Sept Ans, en dépit de travaux importants sur l'histoire militaire et diplomatique, n'a pas été étudiée en fonction des rapports de force à la cour russe, qui vécut à sa manière "un renversement des alliances", le chancelier Bestužev, le futur Pierre III et son épouse Catherine étant ouvertement hostiles à l'adhésion au traité de Versailles associant la France, l'Autriche puis la Russie contre Frédéric II et, dans une moindre mesure, contre l'Angleterre ${ }^{2}$. Élisabeth suivait de près la diplomatie ; se voyant trompée par son chancelier, elle créa la Conférence auprès de la cour impériale le 25 mars 1756 pour prendre en charge la politique extérieure et neutraliser, à court terme, son ministre. La Conférence devint ainsi l'instance suprême de la politique étrangère russe, au détriment du Collège des Affaires étrangères. L'impératrice, qui présidait parfois les séances, rapprocha résolument son pays des nations continentales pour participer à la coalition antiprussienne à laquelle seule sa mort prématurée mit un terme.

Cette prétendue première amitié franco-russe renferme un autre piège : la nature réelle des rapports entre les nations belligérantes du point de vue russe. L'on connait le mépris des Occidentaux pour la "nation barbare", tout au plus reconnue comme alliée stratégique. Un certain nombre de communiqués russes, dont certains sont demeurés inédits, permet d'analyser la vraie position de Pétersbourg face à ses alliés potentiels 
dans les années 1740 (face à l'Angleterre, la Prusse, l'Autriche, la France et la Saxe) et 1750 (France, Autriche et Saxe). Seule l'Autriche bénéficiait de la caution du Collège des Affaires étrangères; la France, alliée de Frédéric II au début des années 1740, recueillait le mépris le plus profond de la cour russe, blessée d'avoir été traitée de "puissance mercenaire » et exclue des négociations d'Aix-la-Chapelle en 1748. Il y avait donc du côté de Pétersbourg aussi une sorte de double diplomatie ou un "secret» de la couronne. L'amitié franco-russe, projetée au $\mathrm{XIX}^{\mathrm{e}}$ siècle sur les systèmes d'alliance de l'époque élisabéthaine, se révèle dans tous les cas de figure trompeuse, les liens avec l'Angleterre n'ayant jamais été entièrement rompus, malgré le soutien que celle-ci apportait à la Prusse et le combat qu'elle menait contre la France outre-Atlantique. Les relations internationales de cette époque doivent être revues à la lumière de la position de la cour de Russie, par rapport au système continental et en fonction de son envergure mondiale en pleine mutation. Les interrogations sur le règne d'Élisabeth sont donc nombreuses et le dépouillement systématique des textes de lois permettrait de renouveler l'histoire d'un règne par trop oublié.

7 V.A. Tomsinov, déjà maître d'œuvre d'un livre intitulé Zakonodatel'stvo imperatricy Anny Ioannovny ${ }^{3}$, comble ainsi une importante lacune en publiant une sélection d'oukases. Il est néanmoins regrettable que leur présentation ne réponde pas aux exigences de l'historiographie actuelle. Les différents décrets, dont le choix est contestable, ne sont pas commentés par des notes. Des 2918 textes de lois publiés dans les volumes 11 à $15 \mathrm{du}$ Polnoe sobranie zakonov rossiiskoj Imperii ${ }^{4}$, un grand nombre émane de la plume de l'impératrice, certains sont signés par le Sénat ou le saint-synode. Tomsinov ne s'est pas donné la peine de faire une classification en fonction du signataire et du contenu des décrets : il serait pourtant aisé de constater qu'élisabeth se concentrait sur la politique étrangère et les questions culturelles. Dans une courte préface, il nous promet une division en sept vastes domaines: 1) aspects juridiques et idéologiques (sic) de l'avènement d'Élisabeth en 1741 ; 2) éducation et science; 3) problèmes gouvernementaux ; 4) droit ; 5) châtiments et punitions ; 6) problèmes diplomatiques ; 7) questions religieuses. Cette structure thématique n'est cependant pas retenue dans la présentation des textes qui s'avère strictement chronologique.

8 Dans la préface, Tomsinov insiste sur le coup d'État d'Élisabeth et les manifestes qui l'ont aussitôt suivi ; en citant avant tout Solov'ev, il justifie cet acte par le droit de la tsarine de succéder à ses parents, Pierre le Grand et Catherine $\mathrm{I}^{\mathrm{re}}$. Il omet de nommer les circonstances de ce putsch, par exemple l'intervention de la France qui avait attisé une guerre entre la Suède et la Russie pour écarter l'armée régulière de la capitale. Le deuxième sujet retenu par l'auteur relève de la politique scientifique; celui-ci évoque longuement le règlement de l'Académie de 1747 et la fondation de l'Université en 1755, mais ne juge pas nécessaire d'évoquer les travaux les plus récents sur ces sujets, entre autres ceux d'Irina Kulakova ou de Dmitrij Kostyšin ${ }^{5}$. Il renonce à évoquer les autres champs thématiques et conclut sa préface par trois oukases dans lesquels l'impératrice ordonne d'installer des chats dans ses châteaux pour en finir avec les souris!

9 Il est à regretter que le maître d'œuvre n'ait pas abordé la politique intérieure, sans doute le sujet le moins connu de ces vingt années de règne. Élisabeth fut la première monarque à abolir de facto la peine de mort; dix ans avant Catherine, elle créa une commission des lois qui devait classer et compléter les textes de lois. Comme son illustre successeur, elle pratiqua une politique d'immigration pour coloniser des zones sensibles de son empire. Le problème du servage n'est guère évoqué, alors que plusieurs lois, 
notamment fiscales, devaient alléger le sort des paysans, sans effet dans la réalité il est vrai.

L'on peut donc louer l'initiative prise par A.V. Tomsinov de publier des décrets d'une époque peu étudiée, mais l'auteur aurait dû se faire aider par des historiens spécialistes du XVIII ${ }^{e}$ siècle, afin que ses manuels deviennent de réels instruments de travail.

\section{NOTES}

1. RGADA (Rossijskij gosudarstvennyj arhiv drevnih aktov - Archives d'État de Russie des actes anciens), fonds 7. Voir à ce sujet l'ouvrage d'Angela Rustemeyer, Dissens und Ehre, Majestätsverbrechen in Russland (1600-1800), Wiesbaden : Harrassowitz, 2006.

2. Voir par exemple L. Jay Oliva, Misalliance: A Study of French Policy in Russia during the Seven Year's War, New York: New York University Press, 1964 ; Herbert Kaplan, Russia and the Outbreak of the Seven Year's War, Berkeley: University of California Press, 1968 ; Petr P. Čerkasov, Dvuglavyj orel $i$ korolevskie lilii [L'aigle bicéphale et le lis royal], M. : Nauka, 1995, p. 79-225.

3. [L'action législative de l'impératrice Anna Ioannovna], M. : Zerkalo, 2009.

4. [Code des lois de l'Empire russe], SPb.: Tip. II otdelenija sobstvennoj E.I.B. Kanceljarii, 1830-1839, 46 vol.

5. Irina P. Kulakova, Universitetskoe prostranstvo i ego obitateli: Moskovskij universitet $v$ istoriko-kul 'turnoj srede XVIII veka [L'université et ses habitants: l'université de Moscou dans l'environnement historico-culturel du $\mathrm{xVIII}^{\mathrm{e}}$ siècle], M.: Novyj hronograf, 2006; Dmitrij N. Kostyšin, Istorija Moskovskogo Universiteta (vtoraja polovina XVIII-načalo XIX veka), Sbornik dokumentov [Histoire de l'université de Moscou (seconde moitié du XVIII ${ }^{\mathrm{e}}$ - début du XIX ${ }^{\mathrm{e}}$ siècle, Recueil de documents], M. : Academia, 2006. 